\title{
Cloud Computing - An Innovative Initiative for Technology Transfer
}

\author{
V. Anandhi* and J. Venkatapirabu
}

Director, Planning and Monitoring, Tamil Nadu Agricultural University, Coimbatore, India

*Corresponding author

\section{A B S T R A C T}

\section{Keywords}

Agricultural

Technology,

Information and

Communication

Technology(ICT),

Cloud Computing

Article Info

\section{Accepted:}

05 February 2020

Available Online:

10 March 2020
As agricultural operations are subjected to vagaries of monsoon, dwindling rainfall, saline, alkaline problems, rising temperature the yield of the crop is drastically reduced and put the farmers at stake. Timely dissemination of need based technology will help the farmers to have precise farm decisions to mitigate the losses. To extend the technology package of practices in crop, livestock, horticulture and allied sectors in a video tablet form would be a ready reckoner. Tamil Nadu Agricultural University has done a stupendous task in delivering and dissemination of agricultural technology run over in decades. In the back drop of Information and Communication Technology (ICT), cloud computing was used to disseminate the information through servers. Those technologies which are really useful and feasible to the farmers for adoption was documented as video clipping and was disseminated to farmers using cloud computing.

\section{Introduction}

Information and Communication Technology (ICT) has taken several strides to reach the unreached. Since, the information and the technologies could not reach the targeted group in time, media comes in handy to disseminate the technologies to empower the farmers. Cloud computing (1) services was used to make the technology feasible, suitable, profitable and viable. The technology supported the farmers with the skill based techniques more lively and vividly, creating a comprehensive package of practices.

\section{Materials and Methods}

The work was carried out with the following aim:

To document the cascade of technologies generated in TNAU for the dissemination in the identified districts.

To identify the ruling technologies of crops of the concerned district under selection for 
video shooting.

To take up the Technology driven initiative for the benefit of small, marginal women farmers, agri entrepreneurs to access the key technologies to solve the problems emanating in a complex cropping systems.

To disseminate the upscale technologies from ploughing to harvesting, beyond postharvest to value addition technologies.

To get instant solutions on the problems emanated in cropping system based knowledge and experience for better management and economic return.

In the era of globalization, information technology has brought out sea change in the lives of rural masses. Earlier mass media like print, radio and Television ruled the roost by striving to the core to impart technical knowledge to lakhs of populace. Still there is a void in the technological reach as it seemed to be costly affair.

To impregnate the concept of seeing believes and to enrich the skills in the advanced farm technology, Video plays a crucial role in the dissemination of innovation.

The ready availability of cloud storage and compute services provides a potentially attractive option for curation and preservation of research information (2). The hardware is reduced to a commodity and the Quality of Services (QoS) are instead provided by a fully integrated (3) Software.

As the video clipping would we more revealing and picturesque, technology may easily be learnt without losing its sheen, thereby providing comprehensive knowledge among the rural people. To augment the productivity video clipping support with technical backup, when floated in mobile computers, pad or else any other information tools would create a lasting impact.

Handy tools like mobile are at the disposal to get acquaintance with technology round the clock. Vital information could be delivered through video clipping by using cloud computing method thereby encouraging adoption rate at the higher order and to bring a trickledown effect.

The ruling technologies of the predominant crops, the ruling variety, promising technologies were identified. The Video Script, Story Board Script and Camera Script was prepared.

Video shooting spots, experimented fields and successful technologies in Research Stations, KVKs, Colleges and the Directorates Concerned was identified. Video clipping was prepared after thorough editing with the well administrated foolproof script. The video clipping was converted in 3GP format / Avi Format.

Dissemination of agricultural technologies through video clipping was be cared out in the identified districts of Tamil Nadu on pilot basis. The targeted area was Tamil Nadu farmers, more specifically Trichirappalli, Erode, Coimbatore, Thiruvaur, Virudhunagar and Vellore.

The extension machineries played a proactive role in reaching out to farmers for getting first-hand information, farmers' perception, and feedback on generated technology and develop new and more appropriate processes, methods and technologies for diverse farm environment. The concept of video clipping tablet would further enrich the skill and knowledge of the farm operations. 


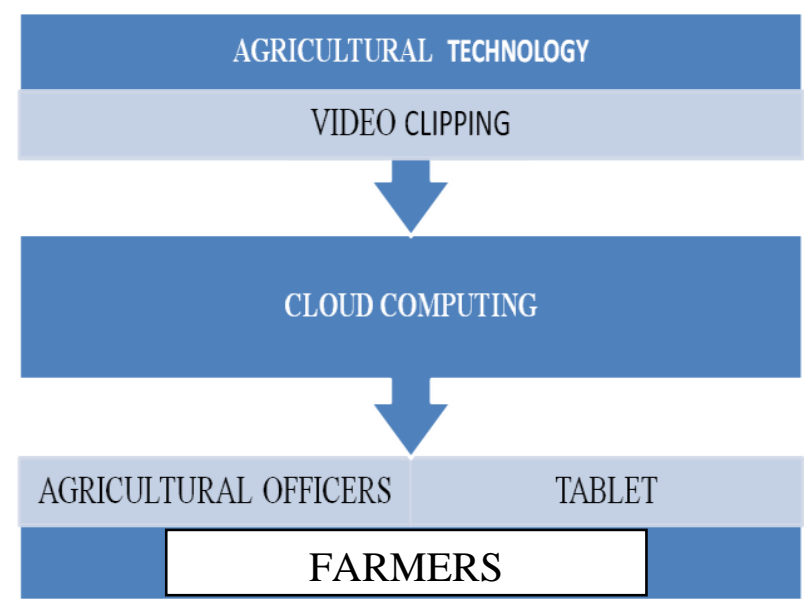

Fig.1 Methodology for Technology Transfer

\section{Results and Discussion}

The vision was in doubling the productivity and tripling the income level, with a missionary objectives and the visionary zeal to enhance productivity. 1000 video clippings was produced on agriculture and allied fields in 3GP format and was disseminated using cloud computing. Video clips imbue the confidence level of the farmers to adopt the scientific technique. The Amazon cloud storage was used and 4170 farmers were benefited through dissemination in various fora.

Timely supply of the techniques and technological intervention was a mandate to ward off the food security crisis by making the farmers sensitize the location specific, need based and user friendly ones helped to improve the standard of living of the farmers.This project was funded by the National Agriculture Development
Programme / Rashtriya krishi Vikas Yojana with an outlay Rs. 147.02 Lakhs. Tamil Nadu Agricultural University played a crucial role through Intervention of cloud storage in the upliftment of farming community as well as the enhancement of productivity and sustaining food security.

\section{References}

1.Mitsuyoshi Hori et al., (Oct 2010). Application to cloud computing to Agriculture and Prospects in other field. FUJITSU Sci. Tech. J., Vol 46, No.4, pp.446-454

2.Waddington et al., (2013). Cloud repositories for research data addressing the needs of researchers. Journal of Cloud Computing: Advances, Systems and Applications 2013, 2:13

3.Thomas Sandholm, Dongman Lee (2014). Notes on Cloud computing principles. Journal of Cloud Computing 3: 21.

\section{How to cite this article:}

Anandhi, V and Venkatapirabu. J. 2020. Cloud Computing - An Innovative Initiative for Technology Transfer. Int.J.Curr.Microbiol.App.Sci. 9(03): 645-647. doi: https://doi.org/10.20546/ijcmas.2020.903.077 